This is a draft version for "Pifarré, M. \& Kleine-Staarman, J. (2011). Wiki-supported collaborative learning in primary education: How a dialogic space is created for thinking together. International Journal of Computer Supported Collaborative Learning, 6(2), 187-205"

\title{
Wiki-supported collaborative learning in primary education: How a dialogic space is created for thinking together
}

\author{
M. Pifarré ${ }^{1} \&$ J. Kleine Staarman ${ }^{2}$ \\ ${ }^{1}$ Universitat de Lleida, Spain. pifarre@pip.udl.cat \\ ${ }^{2}$ University of Exeter, UK. J.Kleine-Staarman@exeter.ac.uk \\ Correspondence address: M. Pifarré. Avinguda de l'Estudi General, 4 \\ 25001 Lleida. Tel: 973 706501973; FAX: 973706502
}

\begin{abstract}
This paper explores how wikis may be used to support primary education students' collaborative interaction and how such an interaction process can be characterised. The overall aim of this study is to analyse the collaborative processes of students working together in a wiki environment, in order to see how primary students can actively create a shared context for learning in the wiki.

Educational literature has already reported that wikis may support collaborative knowledge-construction processes, but in our study we claim that a dialogic perspective is needed to accomplish this. Students must develop an intersubjective orientation towards each others' perspectives, to co-construct knowledge about a topic. For this purpose, our project utilised a 'Thinking Together' approach to help students develop an intersubjective orientation towards one another and to support the creation of a 'dialogic space' to co-construct new understanding in a wiki science project.

The students' asynchronous interaction process in a primary classroom -- which led to the creation of a science text in the wiki -- was analysed and characterised, using a dialogic approach to the study of CSCL practices. Our results illustrate how the Thinking Together approach became embedded within the wiki environment and in the students' collaborative processes. We argue that a dialogic approach for examining interaction can be used to help design more effective pedagogic approaches related to the use of wikis in education and to equip learners with the competences they need to participate in the global knowledge-construction era.
\end{abstract}

Keywords Dialogic teaching - Collaboration - Collective Thinking - Primary Education - Wiki. 
Introduction

Collaboration is a central tenet of the new Social Web. In Web 2.0 technologies, users are active participants who dynamically and collaboratively create new content (Luo, 2010). Online content generation and sharing tools, such as blog writing tools (Blogger, GoogleBlog), wiki software (Wikipedia, WikiSpaces) and photo sharing software (Flickr, Picasa) are used by millions. Organizations such as Nokia, Michelin, IBM and Motorola use blogs and wikis in their marketing and communication campaigns and for knowledge and project management. There can be no doubt that society requires people to possess the adequate skills to participate actively and constructively in collaborative and creative practices (Minocha and Thomas, 2007).

However, some researchers have pointed to discrepancies between the views of learning and knowledge or the goals of the practices implicit in Web 2.0 technologies and educational practices in current schooling. These discrepancies open up new educational challenges concerning the dialectic relationship between personal and collaborative learning, learners' objectives and participation, and the design of pedagogical practices capable of supporting eLearning 2.0 (Bonderup, 2009; Lim, So and Tan, 2010).

Web 2.0 technologies' main educational affordances are communication, interaction and collaborative participation in large communities and in a global perspective: everybody can communicate with everyone and everywhere. These affordances have opened up a new era for learning. We agree with Wegerif (2007 p. 181) that this new era can be described as a "cacophony of voices offering countless opportunities for dialogic engagement with multiple perspectives on every topic." From this point of view, one main issue is how to support our students to create and be engaged in powerful, critical and reflective dialogues using Web 2.0 technologies that help them to co-construct new knowledge through online interaction with others.

Extending this line of argument, our study is aimed to find out how, in a wiki environment, students develop and maintain shared understanding of a science topic, and how students are taking each others' perspective into account. Some researchers have drawn attention to the potential of wikis for collaborative learning, in particular because participants can create a shared digital artefact and this, in turn, may facilitate the development of collaborative learning processes (Moskaliuk, Kimmerle and Cress, 2009; Cress and Kimmerle, 2008). However, while many researchers have described the broad range of potential pedagogical applications for wikis (Lund and Smordal, 2006), few of them have characterised the interaction of participants working in and around wikis with the aim of studying the collaborative construction of meaning through the articulation of each other's thoughts and ideas. In this paper we claim that participation in a wiki collaborative activity requires that participants establish and maintain what Rogoff (1990) and Wertsch (1991) have termed 'intersubjectivity'. Additionally, we draw on Wegerif's notion of opening up and maintaining a 'dialogic space' (2007).

Re-addressing the aim of our study along these lines, we therefore examined the potential of the wiki environment for supporting students' development of an intersubjective orientation towards one another and to support the creation of a "dialogic space" to co-construct new understanding. To this end, we designed, implemented and evaluated a science project in which twenty-five primary students used a wiki environment, with the specific aim of establishing and supporting collaborative interaction, while engaging in a collaborative writing task. 
With our study, we hope to contribute to the discussion about the pedagogical parameters that need to be considered in the design of Web 2.0 supported collaborative learning environments in Primary Education, in order to support students to open up, widen and deepen dialogic spaces for thinking and learning together, in the new global communication era.

\section{Theoretical background}

\section{Collaborative learning}

Socio-cultural theory has fuelled a distinctive interest in social interaction, which, according to theorists in this tradition, lies at the heart of all learning processes (Daniels, 2001; Vygotksy, 1978; Mercer, 2000). A key theme in socio-cultural approaches to learning is to explore how social interaction in joint activities can mediate learning. In recent years a range of work has emerged on socio-pedagogic approaches such as peertutoring, cooperative learning and collaborative learning. Peer-tutoring assumes an asymmetrical relation between partners, and cooperative learning usually involves the sub-division of tasks in which each partner is responsible for one particular aspect of the activity. However, in the current study we have attempted to follow a model of collaborative learning which assumes the relative symmetry of participants in terms of ability, responsibility and engagement with a shared task. Dillenbourg (1999, p. 9) has defined collaborative learning as a situation in which "peers are (1) more or less at the same level and can perform the same action, (2) have a common goal, and (3) work together." In collaborative learning situations, the process of shared meaning making is seen as just as important as the actual outcome of the activity. In this respect, Mercer and Littleton (2007, p. 25) argue that collaboration involves "a co-ordinated joint commitment to a shared goal, reciprocity, mutuality and the continual (re)negotiation of meaning."

A key concept, related to this idea is the concept of 'intersubjectivity', which signifies the process of developing communality in joint activity. According to Rommetveit (1992), intersubjectivity is attained by reciprocal perspective setting and perspective taking. Additionally, Linell (1998, p. 225) argues that, for collaborative projects to be successful and truly collaborative, all parties must be 'mutually otheroriented'. In this respect, Leseman, Rollenberg and Gebhardt (2000) used the concept of co-construction to illustrate the active participation in a collaborative activity, marked by the semantically coherent relations between each participant's contributions to the joint activity.

Matusov (1996; 2001) asserts however, that the notion of intersubjectivity not only deals with having something in common in joint activity. He argues that the concept also stresses the coordination of participants' contributions and emphasises human agency. Following this line of argument, Matusov (2001) proposes that intersubjectivity therefore may also involve the coordination or management of disagreement and misunderstanding among participants, resulting in either a resolution of the disagreement or the development of alternative positions. In collaborative activities, it thus seems crucial that the social interaction is focused on the ideas of the participants 
and that the participants are not only willing to share these ideas, but do so in a respectful and open-minded manner.

In the context of CSCL, Wegerif (2007, p. 181) claimed that it is necessary to develop, through social interaction, a "dialogic space", which he sees as the social realm of the activity within which people can think and act collectively, thus opening up a space between people in which creative thought and reflection can occur. According to Wegerif (2007), this approach offers a new perspective within our understanding of educationally useful dialogue, not only including the aspect of critical thinking supported by the mechanisms of explicit reasoning and knowledge construction but also the less visible but possibly more fundamental processes of reflection and creative emergence.

\section{Can a wiki support collaborative learning processes?}

Wikis are characterized by a variety of unique and powerful information sharing and collaboration features (e.g. Parker and Chao, 2007; Mak and Coniam, 2008; Wheeler, Yeomans and Wheeler, 2008; Cress and Kimmerle, 2008; Larusson and Alterman, 2009). Parker and Chao (2007), for instance, emphasized that properties of a wiki can support collaborative and constructivist learning approaches. A meta-analysis of the literature about the use of wikis confirmed this idea, as wikis appeared to be used primarily for more open-ended activities such as collaborative writing projects. Parker and Chao (2007) also noted that wikis may represent an effective tool for collaborative project-based learning, since wikis can afford the different project work phases, such as designing, planning and documenting. Moreover, the nature of a wiki supports sharing ideas, discussion and reaching agreement on the project's development. Other research on collaborative and argumentative processes in wiki environments (Nussbaum, et al, 2007), found that the wiki helped students to develop an argumentative line of reasoning. Cress and Kimmerle (2009) developed a model to understand social and cognitive processes with wikis.

There seem to be a number of particular characteristics of wiki software that enables the collaborative learning practices described in these studies. Firstly, wiki software enables the collaborative editing of texts and these texts are available to the whole community of users. Users can thus not only create content, they can also hyperlink it to other content, and add, delete and change any part of the shared document. It is important to note here that participants can both add and delete each other's content in the wiki page. Related to this characteristic of wikis is the fact that in general, everyone can edit each other's work without needing special permission to do so.

Another distinctive property of wiki environments is, that the wiki software allows two separate but related collaborative processes to happen simultaneously. In the wiki software, the actual wiki content is written collaboratively on one page, while a tab leads to another page, in which participants may discuss or negotiate about the actual content of the wiki. Using this 'negotiation space', participants may test out ideas for the wiki page and provide reasons for including or excluding particular content, with the aim of reaching consensus on the actual text within the wiki. Shared understanding can thus be arrived at through the negotiation process that takes place between participants. 
In addition, the collaborative writing process in a wiki environment is asynchronous, mediated and indirect. This gives participants the opportunity to reflect on what they read and write in response to their partners' previously written entry. Moreover, all revisions to the wiki page are kept in the wiki history. Users can thus trace the development of the wiki and reflect on the changes in the collaborative work. In our own study, the asynchronous interaction process through the wiki is combined with the synchronous interaction between participants at the computer. Previous studies (sees for instance Kleine Staarman, 2003; Van der Meijden, 2005) indicated that the combination of asynchronous and synchronous interaction enables participants in collaborative activities to combine the specific advantages of synchronous interaction through quick, informal responses, with the advantages of asynchronous interaction, which provides the opportunity to consider work in depth.

Although the features mentioned above are characteristics of wiki design that may enhance the collaborative processes, it remains unclear which pedagogical approach contributes most to successful collaborative learning processes using wikis. Research in the field of computer-supported collaborative learning already indicated that the use of computers cannot be understood by focusing merely on features of the technology or just on the cognitive processes that might be activated when using such resources (Arnseth and Ludvigsen 2006; Strijbos, Kirschner and Martens, 2004). There is a complex interplay between agents, artifacts, and the learning context that weaves resources into a dynamic system.

There are still relatively few research studies on the use of wikis in primary education and, in particular, its impact on collaborative learning processes (Lund and Smordal, 2006). Furthermore, there is little research that focuses on studying the characteristics of the collaborative process that happens when students share, negotiate and create new information in a wiki environment as a means of unfolding how students create understanding through social interaction in a wiki.

\section{The research study}

\section{Purpose of the study}

Our study examined how students engage in collaboration activities that are supported by a wiki environment, and how these processes can be characterized. To this purpose, we will answer the following two research questions:

1. How can the online social interaction in the wiki environment be characterized?

a. When students negotiate in the wiki environment, are they using features of dialogue that can be characterized as collaborative?

b. Can we use the three-part typology of talk, as suggested by Mercer and colleagues (Mercer, 2000; Wegerif and Mercer, 1997) to characterize the social interaction in a wiki environment?

2. In what ways does the collaborative text created in the wiki relate to the interaction process of students in the wiki negotiation page? 


\section{Method}

Twenty-five primary school students participated in this study (9-10 years old). The school is situated in an urban area in Lleida, Spain with mainly socio-economically disadvantaged children. Students worked together in pairs, first at a computer-based science task (Webquest). The wiki environment was used to create a joint informative text about the science topic, together with two other pairs. For the purposes of this paper, we traced and analyzed in depth the work in the wiki environment of two groups of six students.

\section{The task}

The students participated in a science project, spanning 13 one-hour lessons, which were divided into three different phases with distinctive learning objectives (see Figure 1). The first phase was a series of three one-hour lessons with the specific aim to prepare students to collaborate in the wiki environment and to enhance their collaboration process. The content of these lessons was based on the 'Thinking Together' approach (Mercer and Littleton, 2007; Dawes, Mercer and Wegerif, 2000), which is based upon a large body of research on the nature and role of dialogue in classrooms. One of the main findings of this research is that students need to develop their awareness and skills in using talk as a tool for collaborative problem-solving around computers (Mercer, 1994; Wegerif, 2007). In three face-to-face sessions, students were encouraged to set up and reflect upon ground rules for effective communication of ideas in a collaborative situation. In addition, sentence openers were provided as a tool to enhance collaborative talk. Students each had a sheet with five kinds of openers: 1) giving information (e.g., in my opinion); 2) asking for someone else's point of view (e.g. What do you think about; could you give an example) 3) expressing disagreement (e.g., I do not agree with; because); 4) expressing agreement (e.g., I agree with; because) 5) give reasons and summaries the discussions (e.g., to synthesize; we think; so).

In the second phase, during the next three class sessions, students researched the topic they would write about later, i.e., the planet Mars and the scientific possibilities to set up a colony there. Working in pairs, the students undertook a web-based inquiry activity about Mars, which was a new topic for them. In the activity, students had to search, select, integrate and argue about different types of information on the web about Mars. At the end of this stage, each pair wrote an initial propositional text in which they had to present their ideas about the possibility of setting up a colony on Mars and the potential difficulties that would need to be overcome.

In the third phase of the project, three pairs of students were grouped together in the wiki environment in order to write a collaborative text about Mars (in the rest of the paper, these groups will be referred to as 'Group 1' and 'Group 2'). The starting point for the students were the three initial texts written in phase two, which were already placed in the wiki environment for everyone to read and edit. This last phase lasted seven one-hour sessions, of which the first one was used for familiarizing the students with the wiki environment. In this session, the teacher also re-emphasized the features of collaborative talk as discussed in the first phase of the project. 


\section{The Wiki Project}

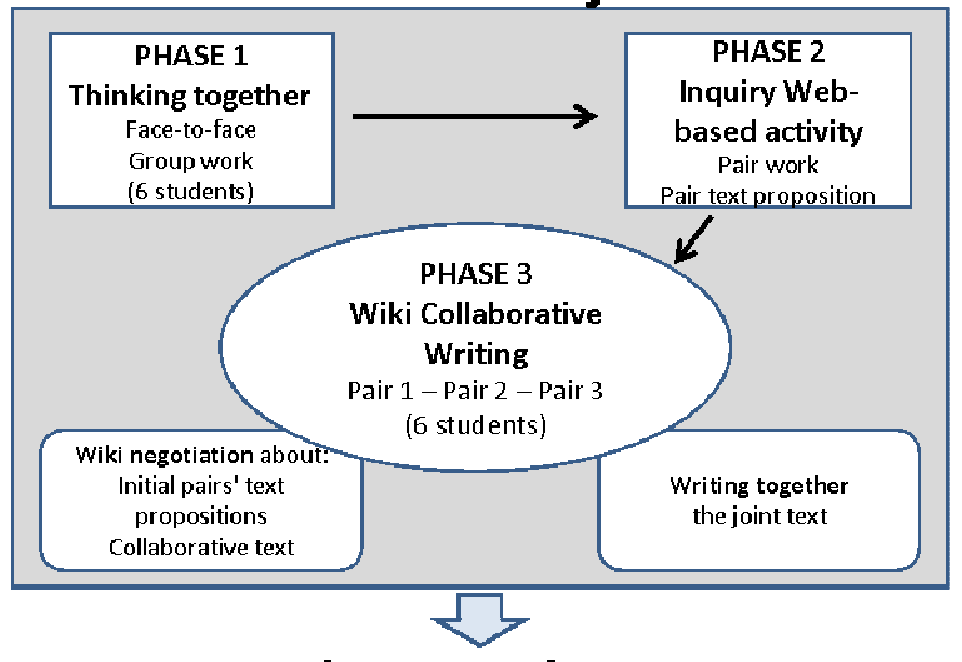

Final Collaborative Text

Figure 1: Diagram of the different phases of the wiki project

In the next six sessions, pairs took turns to work in the wiki for periods of about 1015 minutes. In total, each pair spent between seven and eight periods working in the wiki environment (a total of 21 periods for Group 1 and 24 for Group 2 over the six sessions).

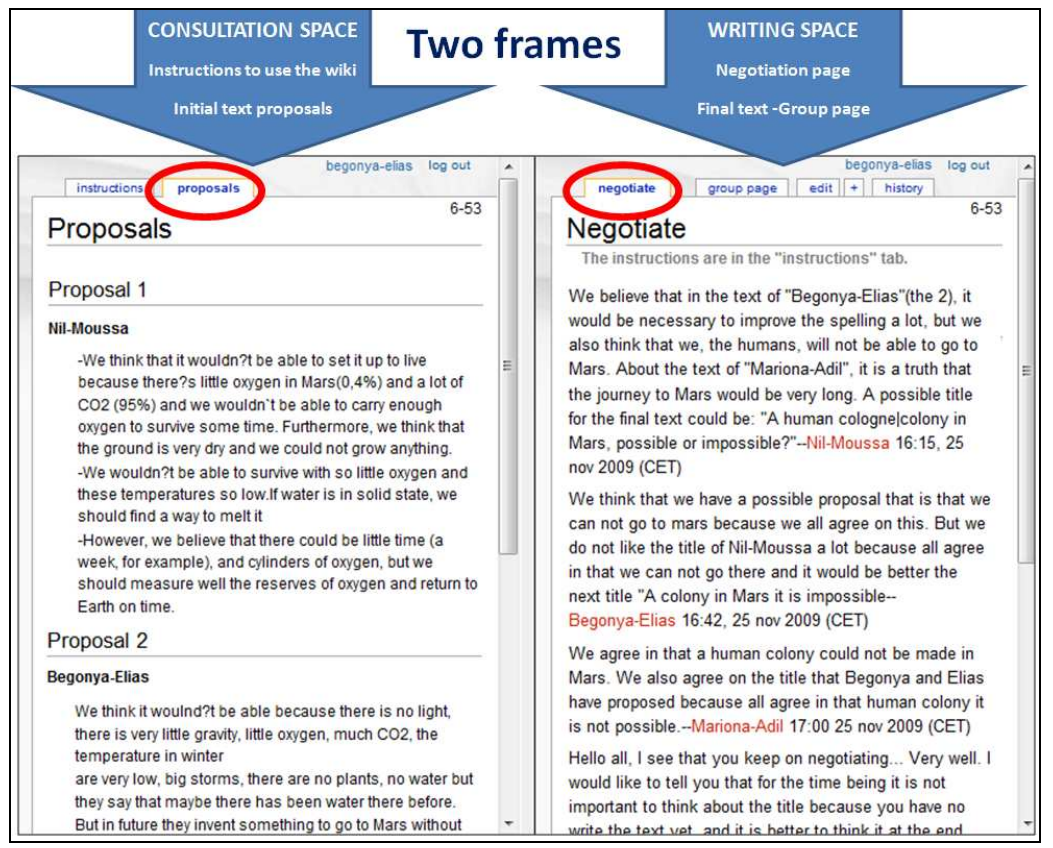

Figure 2: The lay out of the wiki environment (the screenshot has been translated to English).

The wiki environment used in the project was 'MediaWiki' and a specific lay-out was designed which consisted of two vertical frames with a movable dividing line between them. The left frame was called the 'consultation frame' while the right frame was the 'writing frame' (see Figure 2). Within the consultation frame, there were two 
tabs, under which the students could find the instructions for using the Wiki and the initial texts. The right frame was called the "writing frame" and there were also two tabs, one of which linked to the 'negotiation space'. In this space, the students were asked to discuss and reach agreement about what to include in their final collaborative text. As in the second phase of the project, students were encouraged to use the sentence openers in their wiki discussions, which were displayed on a sheet of paper for reference. The second tab in the "writing frame" linked to the 'group space', which was the space in which the three pairs together had to write their collaborative text

\section{Data collection and analysis}

The data for the current study was collected during the seven wiki sessions in phase three of the project. We collected all the contributions in the different spaces of the wiki environment and these were analyzed in depth. Our analysis approach has strong links with a methodological framework called Sociocultural Discourse Analysis (Mercer, 2005). This framework draws together a range of methods, both qualitative and quantitative, with the aim of studying the nature and functions of language for the pursuit of joint intellectual activity. Sociocultural Discourse Analysis of language in classroom focuses on the linguistic, psychological and cultural aspects of language and the analysis moves between the detail of specific contributions to the online discussion and the broader meanings from analyzing more extended episodes of interaction.

We began our analysis process with the search for the presence of key words that may indicate reasoning and collaboration. For this reason, we used a computer-based concordance analysis programme (Wordsmith Tools), to count and compare the relative incidence of key words that are associated with collaboration, reasoning and exploratory talk in the negotiation spaces of both groups under investigation. All the contributions to this discussion were included in the analysis and these were searched for the following key words that indicate collaboration (Barnes and Todd, 1977) and reasoning (Mercer and Wegerif, 1999):

a) Collaboration words. Hem/em (we have); tenim (we have/ we have to); estem (we are); raó (right/agree); també (too); tots (all);

b) Reasoning words: Creiem (we think); pensem (we think); considerem (we consider); exemple (example); altra banda/un altre punt de vista (from other point of view); si no/si (if/ if not); seria/hauria/podria/podríem (conditional); expliqueu (explain); perquè/per què/perque/perquè (why, because); però (but); així (therefore)

The second stage of the analysis process consisted of exploring and characterizing the nature of interaction of students in the wiki. Our research question at this stage was: 'How can the online wiki negotiation process be characterised?' As a starting point for the analysis, we used Mercer's tree-part typology of talk: Disputational Talk, Cumulative Talk and Exploratory Talk (Mercer, 1994). In line with previous research of Mercer and colleagues (see for example Kleine Staarman, 2009; Kleine Staarman et al, 2005; Mercer, 2008; Wegerif and Dawes, 2004) we used this typology of talk as a heuristic frame of reference, which enabled us to examine the initial variety of interaction in the wiki. Disputational Talk is interaction in which participants' views are challenged without justifications. In contrast, Cumulative Talk is interaction in which students build upon each other's ideas without critical engagement. Combining elements of both, Exploratory talk can be characterised by sharing of information, 
giving reasons and alternatives and aiming to reach agreement (Mercer, 2000). In addition, Barnes and Todd (1977) characterize interaction of a collaborative nature as containing questions and statements of explicit agreement.

In order to answer the second research question: 'In what ways does the collaborative text writing process relate to the interaction process of students in the wiki?' we examined the final collaborative texts of the students and compared these to their initial text proposals.

\section{Findings}

\section{The quality of the wiki negotiation: Indicators of reasoning and collaboration}

In this section we would like to address the first research question, which was: 'How can the online social interaction in the wiki environment be characterised?'

The objective of this first stage in the analysis is to draw a general picture of the students' interaction and negotiation processes in the wiki. First, we wanted to know whether it included the key words presented in the method section that are associated with collaboration, reasoning and Exploratory Talk and how these key words were distributed during the students' negotiation process in the wiki.

Analysing the negotiation process of both groups, it can be seen that both groups studied showed a similar pattern of interaction. Firstly, the groups show a similar length of their interactions in the negotiation space (G1: 802 words; G2: 994 words). As can be seen in Figure 3, keywords associated with collaboration and reasoning are evenly distributed throughout the negotiation process. The Figure is derived from the computer-based text analysis software that was used for the analyses (Wordsmith Tools) and it indicates the number of times (hits) a particular word appears in the text and also its distribution within the text as a whole. This analysis confirms that students use key words associated with collaboration and group reasoning processes in their wiki negotiation process, This data can be seen as an indicator that the students were indeed collaborating and discussing their contribution during all their collaborative work in the wiki environment. 


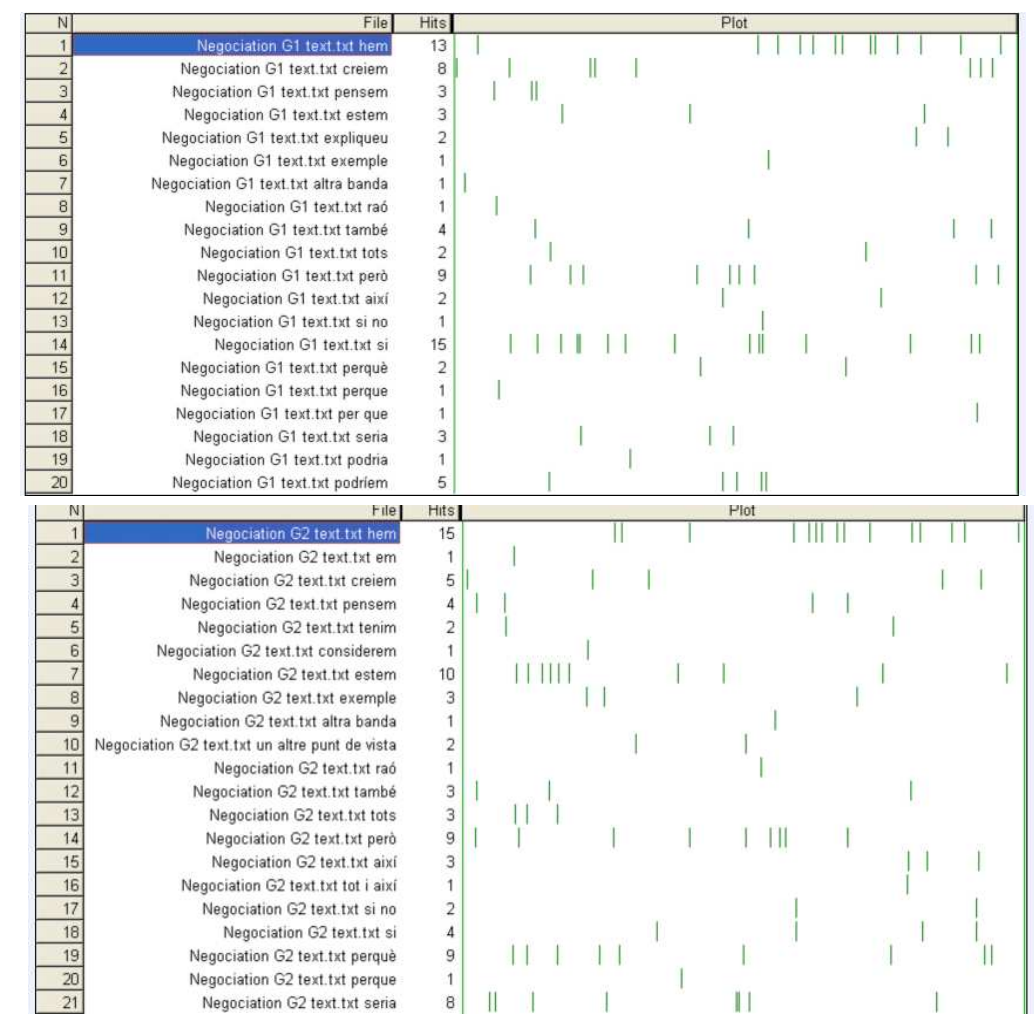

Figure 3: Number of times a word was mentioned (hits), the total of words in the text (words) and the dispersion plot in Group 1 (G1) and in Group 2 (G2).

Hem/em (we have); creiem (we think); pensem (we think); tenim (we have to); considerem (we consider); estem (we are); exemple (example), altra banda/un alter punt de vista (from other point of view); tots (all); si no/si (if); seria/hauria/podria (conditional); expliqueu (explain); perquè/ per què (why, because)

\section{The establishment of a shared collaborative practice through wiki}

In this section, we will focus on how the students created and maintained their shared collaborative activity in the wiki environment. To do so, we analysed student's contributions in the wiki in terms of their intersubjective orientation; in particular, we focused on characterising the interaction as Exploratory, Cumulative or Disputational in nature. For this, we took into account students' contributions in the negotiation space, but we also considered the content of their writings in the group space (the collaborative text). The unit of analysis of students' contributions in the wiki negotiation space was an "Episode". In our study, an episode was a cluster of contributions in which students showed a common objective in order to fulfil the task and with a particular dialogic style (Mercer, et al, 2010).

The contributions of both groups of students in the wiki negotiation space can be divided into four different episodes, each with a different aim and each with its own particular dialogic style. As can be expected, these four episodes are strongly related to the task and a similar division can be seen in other studies about the topic of 
collaborative writing (see for instance Andriesen et al, 2003). In the following subsections we will present a more detailed description of these episodes in relation to the student's intersubjective orientation.

\section{Episode 1: Content generation - Exploratory intersubjective orientation}

In this first episode, the aim for the students seemed to be to generate shared content and to plan the collaborative writing process. Students only wrote in the negotiation space and the contributions of both groups of students indicate an exploratory orientation. The three pairs in each group had to write a joint text, and in doing so, they had to make sure they discussed all the ideas that were present in each of the initial text proposals. To do this, the first cluster of contributions seemed to be aimed at making explicit the common ideas and finding commonality in ideas and arguments. Students showed an explicit effort to try to construct common knowledge which would enable them to start writing the collaborative text. They also re-elaborated their own and others' ideas and gave explicit reasons to support these, as a means of giving enough value to their ideas for them to be included in the collaborative text. Providing reasons, justifications, warrants and/or evidence to support one's opinions is an important aspect of argumentation, and is central to the notion of Exploratory Talk (Mercer, 2000; RojasDrummond and Peón, 2004). Extract 1 illustrates the construction of common knowledge in order to write the shared text.

\section{Extract 1 (group 1):}

Pair 1: We also think that if it was possible [to travel to Mars] we had to travel regularly to the Earth to take things we'd need, such as oxygen. Could we all agree about travelling to the Earth regularly?

Pair 2: We believe that it would be possible to travel to Mars. We also believe that we have to increase the capabilities of living in Mars. We would have to carry spare water to Mars in case it runs out. We'd have to carry very big tanks, at least 1 for each day of the week

In Extract 1, students ask explicitly and critically for more reasons for their arguments and clarifications for their ideas. This could help the students to make their ideas more visible and make them seem more elaborated, which, in turn could encourage the other pairs to incorporate them into the final shared text. In these critical first contributions to the negotiation process, students also identify and evaluate inconsistencies in each others arguments and propose alternatives, which are illustrated by Extract 2 .

\section{Extract 2: Contribution of Pair 2 (group 2)}

We agree with you in that it would be necessary to carry a lot of food to go to Mars. But B$E$, What things could we invent to travel to Mars without any dangers? Could you give an example? We consider that the final text should start with: We "believe that a human colony will not be able to be established in the Mars planet because..." 
In this first episode there are also contributions that aim to summarize main ideas and arguments, which are subsequently agreed upon by all group members during the discussion. These summaries are considered as ideas that can be written in the collaborative text. An example of this can be seen in Extract 3.

\section{Extract 3: Contribution of Pair 1 (group 1)}

We all agree that it's possible to travel to Mars but it's not possible to live on Mars because there is so much carbon dioxide.

At the end of this first episode, both groups propose a specific organization for the collaborative text. This proposal is agreed upon in both groups and elaborated further by the other members of the group. This seems to be a key stage in that it helps the collaborative process to move forward to the actual start of the writing of the collaborative text. In Extract 4, an example of this stage of one of the groups studied can be seen.

Extract 4: Proposition of the organisation of the collaborative text (pair 1, group 2)

We believe that the final text should have the following sections:

. Our opinion about if it would be possible to go to Mars and for how much time.

. The obstacles that it will have to deal with.

. How we could overcome them (the difficulties)

To conclude, it seems that, in this first episode, the students showed many features of Exploratory Talk, in the same way as Mercer and colleagues described. Additionally, we would argue that the students used language to open up a space for thinking together. Through their way of working together, students developed a relationship in which they expected challenges and alternatives, and their use of language helped them to open up a dialogic space and time for reflection allowing for a schematic proposal for the collaborative text to emerge. Their intersubjective orientation was one that was focused on trying to find communality, but at the same time left open possibilities for reasoned disagreement.

Previous research findings also indicate that the use of Exploratory Talk had a positive effect on children's joint problem solving (Wegerif and Mercer, 2000) because it seems that children who have developed reasoning and argumentation skills, can harness these in their joint efforts to solve a complex academic task. In the current study, we could argue that the exploratory intersubjective orientation of the students at the beginning of the task may have helped them to write a more complex, accurate and reasoned text in the later stages of the project.

\section{Episode 2. Text generation: Cumulative intersubjective orientation}

This episode seemed to be focused on the joint generation of text and as such, the students' contributions are mainly featured in the Group Space, in which the joint informative text was written. In this part of the task, all the pairs took turns in writing 
the collaborative text. In both groups that were studied, the three pairs contributed actively to the writing of the collaborative text. The students were mainly involved in adding those ideas that were agreed upon in the previous episode. In both groups, one pair seemed to take the lead at the start of the writing process and these pairs also took a coordinating role. These two 'leader pairs' displayed a responsible and collaborative style of leadership, in that they included all the ideas proposed and agreed upon earlier in the group text. The other two pairs in both groups tried to improve the text by adding new arguments to the collaborative text, expanding or reorganizing previous ideas.

In this episode, we would argue that the collaborative work of the students resembles a cumulative style of interaction. Students built positively but rather uncritically on what the other pairs had done and the pairs mainly used the interaction to construct 'common knowledge' through the accumulation of ideas. According to Mercer (1994), cumulative discourse is characterized by repetitions, confirmations and elaborations. In this episode, students constructed their common knowledge by taking into account the collaborative negotiation in the previous episode and by accumulation of new ideas.

We would argue that the cumulative orientation of this episode is lead by the characteristics of the collaborative task: writing. Previous studies on children's writing processes also show that the first stage in children's writing is characterized by telling and transcription of ideas. Young writers seem to focus their cognitive effort on transcribing ideas in order to write a longer text (Bereiter and Scardamalia, 1987). However the students in our study only seem to use the ideas agreed collaboratively in the previous episode. Perhaps because of the distribution of roles among the different pairs, all the pairs contributed actively to the text and ideas proposed by all the different pairs are included in the collaborative text.

\section{Episode 3. Making the text longer, richer and complex: Cumulative intersubjective orientation with co-construction}

In this third episode, the students are engaged with the sharing of new ideas to deepen and widen their existing text. Students wrote both in the negotiation page and in the group page and their contributions seemed to be written with the following three collaborative purposes:

1. To share new ideas for the collaborative text, which were presented with reasons and arguments. An example of this can be seen in Extract 5:

\section{Extract 5: contribution of Pair (group 2)}

We have not added anything to the final text, but we think that we could make a paragraph saying that in the future we might go, and some examples of a new invention to go to Mars and some way to be able to transport the oxygen in Mars

2. To discuss about the arguments written in the text.

Although students did not delete ideas from the collaborative text, they did contribute critically, identified inconsistencies in others' arguments and proposed alternatives. In addition, they expressed their disagreement in the negotiation space, and waited for the pair who had written the idea to change, correct or remove it. Even so, in general, students were very respectful about each other's ideas, as can be seen in Extract 6 . 


\section{Extract 6: Contribution of Pair 1 (group 2)}

$M-A$, we do not agree with you in that a space suit would solve the problem of oxygen, because the problem that we have is that we could not transport enough oxygen to survive for a while rather than the fact that the dresses weigh too much or are very uncomfortable. Even so, it is a good idea. We have also corrected some mistakes in the final text.

3. To make visible their thinking and explain the others what they had written in the collaborative text.

Students gave explicit reasons for the changes they made in the collaborative text. In doing so, the students made their knowledge more publicly accountable and reasoning became more visible in their negotiation.

To sum up, in this episode, students also seem to take on a cumulative intersubjective orientation, but with an additional perspective of co-construction (Rojas-Drummond, et al, 2010). The difference between a cumulative orientation and a co-constructive orientation is that with a cumulative orientation, students would be merely engaged in adding new ideas and arguments to the final text. In the current episode however, the students were focused on making the text richer and longer and to do so, they felt that each others' ideas could help them to reach this common objective. Although students do not constructively critique others' ideas, in this episode students expanded and reelaborated others' ideas with new arguments. From our point of view, this indicates how students widen and broaden their space of dialogue, increase the degree of difference between others' perspectives and make their discussion and the text richer and more complex. It can be argued that, by explicating and acknowledging the differences between them, students can use their disagreement as a stepping stone for advancing their own ideas about the topic (Matusov, 2001).

Various authors claim that the presence of cumulative and co-constructive type of dialogue can support creative thinking, since it opens up a reflective space which supports the open exploration of possibilities (Rojas-Drummond et al, 2010; Wegerif, 2007).

\section{Episode 4. Finishing the collaborative text: Disputational orientation.}

This last episode was focused on coordinating key activities and ideas in order to finish the joint text. One of the groups that we studied focused in particular on the title of their text while the other group focused on arguing about improving one idea in their text (how much time humans could survive on Mars). This episode can be characterised by a Disputational orientation. In contrast to the elements of disagreement that may occur when people have an exploratory or co-constructive intersubjective orientation, disagreement in a disputational orientation is not characterised by open-mindedness and reasoning, but rather by one-sided, individual decision making. An example of this process can be seen in Extract 7: 
Extract 7: Contributions of Pairs 1 and 2 (group 2)

Pair 1: We continue to think that a suitable title would be: "A human colony in Mars, possible or impossible"? We believe that it gives more interest to the final text. We have written it on the group page.

Pair 2: We have changed the title of the final text and now is: A human colony in Mars an impossible dream.

Pair 1: We changed the title again. M-A [the third pair], you could choose the option that you find more suitable and write it in the final text (with no mistakes). If not, we could be discussing the title all day long.

One explanation for the disputational nature of the student's discussion might be that students were focused on finishing the collaborative text in time and they may have felt they would lack the time to discuss and negotiate ideas in full. In their interaction, the pairs engaged in short exchanges of assertions and reasons. In one of the groups one pair made several individual decisions to finish the text; they deleted one idea, which they felt was incoherent and added another idea, although in doing so they did take into consideration the other pairs' contributions.

\section{Analysis of the collaborative text}

In this section, we will analyze some features of the collaborative text written by the students. The objective of this section is to answer our second research question "In what ways does the collaborative text relate to the interaction process of students in the wiki?"

To answer this question we will compare the first text proposition written by the pairs in the second phase of the project and the collaborative text written by students using the Wiki environment in the third phase of the project. Our intention was to examine some quantitative features that could indicate in what ways the collaborative process analyzed in the previous sections has influenced the ways in which the initial pairs' ideas were incorporated, deepened and widened in the final group text. Specifically, we will compare the length (i.e., number of words) of the different texts, the number of t-units; the number of scientific ideas and the number of reasoning connectors (e.g., because, however, if, but, also, besides, for example, moreover). In our work, a t-unit is the shortest grammatically allowable sentences into which writing can be split. Often, but not always, a T-unit is a sentence.

Table 1 displays the quantitative features of the texts written in pairs as result of the inquiry web-based activity (phase 2 of the instructional process) as well as the quantitative features of the text written collaboratively by the three pairs of each group in the Wiki environment. 


\begin{tabular}{ccccc}
\hline Text & $\begin{array}{l}\text { Number } \\
\text { paragraphs }\end{array}$ & $\begin{array}{c}\text { of } \\
\text { Number } \\
\text { of words }\end{array}$ & $\begin{array}{l}\text { Number } \\
\text { of t-units }\end{array}$ & $\begin{array}{l}\text { Number of } \\
\text { reasoning } \\
\text { connectors }\end{array}$ \\
\hline $\begin{array}{l}\text { Initial text } \\
\text { G1 - Pair 1 }\end{array}$ & 1 & 61 & 6 & 2 \\
\hline $\begin{array}{l}\text { Initial text } \\
\text { G1 - Pair 2 }\end{array}$ & 1 & 11 & 1 & 0 \\
\hline $\begin{array}{l}\text { Initial text } \\
\text { G1 - Pair 3 }\end{array}$ & 3 & 91 & 5 & 4 \\
\hline $\begin{array}{l}\text { Collaborative } \\
\text { text Group 1 } \\
\text { Pairs 1-2-3 }\end{array}$ & 4 & 119 & 10 & 9 \\
\hline \hline $\begin{array}{l}\text { Initial text } \\
\text { G2 - Pair 1 }\end{array}$ & 3 & 110 & 8 & 3 \\
\hline $\begin{array}{l}\text { Initial text } \\
\text { G2 - Pair 2 }\end{array}$ & 1 & 94 & 4 & 4 \\
\hline $\begin{array}{l}\text { Initial text } \\
\text { G2 - Pair 3 }\end{array}$ & 1 & 88 & 6 & \\
\hline $\begin{array}{l}\text { Collaborative } \\
\text { text Group } \\
\text { Pairs 1-2-3 }\end{array}$ & 4 & 184 & 10 & 8 \\
\hline \hline
\end{tabular}

Table 1: Quantitative features of the different texts written by the students. The shaded boxes indicate the texts written collaboratively in the Wiki environment. G1= group 1; G2=group 2.

In terms of number of words and t-units, it must be noted that students' contributions are longer in the collaborative text group than in each of the initial texts written by the pairs. Moreover, the longer texts are richer and more accurate, based on an increase in the number of t-units. These results echo the findings of Mak and Coniam (2008) in that students engaged in collaborative writing using Wiki tended to produce longer t-units and demonstrated greater complexity in their writing.

Moreover, the structure and organization of the ideas in the collaborative text also seem more accurate than in the initial texts. Students organized their ideas in different paragraphs and both groups introduced a title and a conclusion. In this line of argument, Cress and Kimmerle (2008) claimed that key collaborative learning processes could be developed with the help of wikis, which included student engagement in activities related to the integration of previously contributed ideas and reorganizing and rewriting of complete paragraphs.

The number of reasoning connectors also increased in the collaborative text compared with the pairs' initial text propositions. It could be argued that this is another indicator that demonstrates that the students went deeper into argument chains, elaborated upon the meaning of arguments, and better understood the concepts involved. This finding echoes our findings reported in the previous paragraphs, in that the increase of words associated with reasoning processes positively influences the effectiveness of the students' reasoning and argumentative processes.

From our perspective, this analysis indicates that the product of students' collaborative work is more than the sum of the initial pairs' work. It can be argued that the collaborative processes developed by students in the wiki environment, which, as we demonstrated earlier, was characterised by openness of ideas and the widening and deepening of a creative dialogic space, may have been an important factor in helping the students to write a joint, collaborative text. 


\section{Discussion and conclusions}

This paper proposes an alternative view of the pedagogic issues that need to be taken into account when wikis and web 2.0 technologies are used in classrooms. There are quite a number of studies that emphasize the cognitive processes that wikis can promote, but in this study, we claim that a dialogic perspective is also needed.

The overall aim of this study was to analyse the collaborative processes of students working together in a wiki environment, to unfold how primary students actively create their own, shared context for learning in the wiki. In doing so, we adopted a dialogic approach to studying the interaction of the students, and aimed to characterise the interaction process in terms of students' intersubjective orientations. We based our analysis on the characterisation of discourse in terms of Disputational, Cumulative and Exploratory talk, as proposed by Mercer and colleagues (Mercer, 2000), which was also used to characterize dialogue in computer-mediated communication environments (Wegerif and Dawes, 2004). This characterisation helped us in providing a heuristic framework, capable of capturing, in a holistic manner, the dialogic nature of the collaborative process in a wiki. We would argue that a dialogic approach such as this is needed to analyse interaction in a complex environment such as the one utilised in the current study, to be able to take into account the collaborative dimension of computersupported collaborative learning.

In addition, we feel that this way of examining interaction can be used to help to design a more effective pedagogic approach related to the use of wikis in education, in order to equip learners with the competences they need to participate in global knowledge construction. A dialogic approach to teaching is widely reported in educational literature (see for example Alexander, 2008) and others have reported a connection between the nature and functions of dialogic teaching and the development of student's abilities to create, sustain and utilise the dialogic space offered by welldesigned, ICT-supported collaborative learning activities (Mercer et al., 2010). By adopting a dialogic approach to the design of CSCL learning environments, educators may be able to unpack the collaboration processes of students during their collaboration in the wiki and they may subsequently be able to diagnose and scaffold key missing aspects of this process.

There seem to have been several specific characteristics of the pedagogic design of the activity in our study that supported students' joint interaction processes in the wiki environment. Firstly, the fact that every pair provided their own ideas in an initial text proposition seems to have been helpful in giving a 'voice' to all members of the group from the beginning of the collaborative work. It enabled all the pairs to be orientated to each others' ideas from the start and enhanced their active participation in writing the collaborative text.

Secondly, we argued that students needed to develop an exploratory or coconstructive intersubjective orientation towards other participants' perspectives, to be able to co-construct knowledge about a topic. For this purpose, the project utilised a "Thinking Together" type approach to help students to develop an intersubjective orientation towards one another, that was based upon Exploratory Talk, which supported the creation of a "dialogic space" to co-construct new understanding. The implementation of this model proved to be a significant improvement in the quality of 
collaborative learning and reasoning according to a range of measures (Wegerif, Perez Linares, Rojas Drummond, Mercer \& Velez, 2005; Mercer, 2000).

Thirdly, another key characteristic of collaborative use of wikis seems to be that the end product is one that is created collectively. In a wiki, users can modify existing entries, as indeed the students in our study did. From a perspective of co-construction, users might get the sense that they are creating a truly shared digital artefact as the product of their collaboration. In doing so, the co-construction processes may encourage users to take into account other's opinions and, subsequently, increase their knowledge (Moskaliuk, Kimmerle \& Cress, 2009). Moreover, through shared work in a wiki environment, a sense of community may develop, which, in turn, may lead to intersubjectivity and co-construction in the ways we described earlier.

Although in the current project the students indeed worked jointly on one common artefact, students did not create links to existing pages, and neither have they produced media other than text (i.e., images). This may have been a result of the fact that the students and the teacher were relative novices in wiki use for educational purposes. Moreover, the wiki engine that was used (MediaWiki) has an encyclopaedic orientation (exemplified by the well known Wikipedia), which may have influenced the students' and teacher's perceptions of what was appropriate in terms of content in the wiki. In future work, we intend to explore the design of a learning activity that supports the use of visual representations, as well as links to existing pages, as additional and potentially powerful affordances for collaborative knowledge construction.

Fourthly, as wikis enable asynchronous collaborative processes, students have time to read and think about others' contributions. This characteristic can support coreflective processes about others' ideas, thoughts, arguments and information. These coreflection processes can, in turn, lead to reconstruction and reorganization of experience, which adds to the meaning of the experience (Clark, 2009). In our study, students engaged in co-reflection processes in terms of collaborative critical thinking between individuals and pairs of students, who explored their experiences in order to reach new intersubjective understandings and appreciations (Yukawa, 2006).

To conclude, this paper illustrates how specific characteristics of wikis are harnessed by children to create a shared dialogic space in which these students are open to oneanother's ideas and where they use these ideas to solve the task together. We would argue that the nature of the students' contributions indicate that they were actively discussing each other's ideas, providing reasons and justifications for them and building constructively on ideas from others. Through the use of the wiki, and the pedagogic design of the learning environment, the students were supported in collaborative processes that may facilitate the joint creation of new understanding. The development of the digital competences needed for collaborative knowledge creation is highlighted as crucial for students in order to participate actively in the global knowledge-construction processes afforded by Web 2.0 technology. In this respect, the project described in this paper aimed to shift the roles of pupils from 'consumers' of Web 2.0 technologies to 'creators' of new Web 2.0 content. As a consequence of this shift, we would claim that it is equally important to develop a pedagogic model that is capable of leading children through this shift and helping them to participate in the new global thinking and creative processes that are emerging within the use of current technology. 


\section{Acknowledgements}

This research was funded by the Ministerio de Ciencia y tecnología of the Spanish Government (project number: EDU2009-11656). The authors are very grateful to the teacher and the pupils for their participation in the study reported in this paper and to the research assistants of the COnTIC research group of Universitat de Lleida. We would also like to thank Rupert Wegerif for his constructive comments on earlier drafts of this article.

\section{References}

Alexander, R. (2008). Towards dialogic teaching: Rethinking classroom talk. 4th ed. York, England: Dialogos.

Andriesen, J., Erkens, G., van de Laak, C., Peters, N., \& Coirier, P. (2003). Argumentation as negotiation in electronic collaborative writing. In J. Andriessen, M. Baker, \& D. Suthers (Eds.), Arguing to learn. Confronting Cognitions in ComputerSupported Collaborative Learning Environments. Netherlands: Kluwer Academic Publishers.

Arnseth, H., C. \& Ludvigsen, S. (2006). Approaching institutional contexts: Systemis versus dialogic research in CSCL. International Journal of ComputerSupported Collaborative Learning, 1 (2), 167-185.

Barnes, D., \& Todd, F. (1977). Communication and learning in small groups. London: Routledge \& Kegan Paul.

Bereiter, C. \& Scardamalia, M. (1987) The Psychology of Written Composition. Hillsdale, NJ: Erlbaum.

Bonderup, N. (2009). Inherent tensions and evident challenges for education. International Journal of Computer-Supported Collaborative Learning, 4, 343-363.

Clark, P. (2009). Reflecting on reflection in interprofessional education: implications for theory and practice. Journal of Interprofessional Care, 23 (3), 213-223.

Cress, U \& Kimmerle, J (2008). A systemic and cognitive view on collaborative knowledge building with wikis. International Journal of Computer-Supported Collaborative Learning, 3, 105-122.

Daniels, H. (2001). Vygotsky and Pedagogy. London: Routledge/Falmer.

Dawes, L., Mercer, N., \& Wegerif, R. (2000). Thinking together: A programme of activities for developing thinking skills at KS2. Birmingham: The Questions Publishing Company Ltd.

Dillenbourg, P. (1999). Introduction: What do you mean by "collaborative learning"? In P. Dillenbourg (Ed.). Collaborative learning: Cognitive and computational approaches. Amsterdam: Pergamon.

Kershner, Mercer, Warwick \& Kleine Staarman (2010). Can the interactive whiteboard support young children's collaborative communication and thinking in classroom science activities? International Journal of Computer-Supported Collaborative Learning 5 (4) 359-383. 
Kleine Staarman, J. (2003). Face-to-face talk to support computer-mediated discussion in a primary school literacy practice. Reading, 37(2), 73-80.

Kleine Staarman, J., Krol, K., Van der Meijden, H. (2005). Peer interaction in three collaborative learning environments. Journal of Classroom Interaction 40(1), 29-39.

Kleine Staarman, J. (2009). The joint negotiation of ground rules: Establishing a shared collaborative practice with new classroom technology. Language and Education, 23(1), 79-95.

Larusson, J. A., \& Alterman, R. (2009). Wikis to support the "collaborative" part of collaborative learning. Computer-Supported Collaborative Learning, 4, 371-402.

Leseman, P. P. M., Rollenberg, L., \& Gebhardt, E. (2000). Co-construction in kindergartners' free play: Effects of social, individual and didactic factors. In H. Cowie \& G. Van der Aalsvoort (Eds.). Social interaction in learning and instruction: The meaning of discourse for the construction of knowledge. Amsterdam, Netherlands: Pergamon/Elsevier Science Inc.

Lim,. W-Y., So, H-J. \& Tan, S-C. (2010). eLearning 2.0 and new literacies: Are social practices lagging behind? Interactive Learning Environments, 18 (3), 203-218.

Linell, P. (1998). Approaching dialogue: Talk, interaction and contexts in dialogical perspectives. Amsterdam: John Benjamins Publishing Co.

Lund, A. \& Smordal, O. (2006). Is there a space for the teacher in a wiki? In Proceedings of the 2006 International Symposium on Wikis (WikiSys 06) (pp. 37-46). Odense, Denmark: ACM Press.

Luo, L. (2010). Web 2.0 Integration in Information Literacy Instruction: An Overview. The Journal of Academic Librarianship, 36 (1), 32-40.

Mak, B., \& Coniam, D. (2008). Using wikis to enhance and develop writing skills among secondary school students in Hong Kong. System, 36, 437-455.

Matusov, E. (1996). Intersubjectivity Without Agreement. Mind, Culture and Activity, 3(1), 25-45.

Matusov, E. (2001). Intersubjectivity as a way of informing teaching design for a community of learners classroom. Teaching and Teacher Education, 17, 383-402.

Mercer, N. (1994). The quality of talk in children's joint activity at the computer. Journal of Computer Assisted Learning, 10(1), 24-32.

Mercer, N. (2000). Words and Minds: how we use language to think together. New York, USA: Routledge.

Mercer, N. (2005). Sociocultural discourse analysis: analysing classroom talk as a social mode of thinking. Journal of Applied Linguistics, 1(2), 137-168.

Mercer, N., \& Wegerif, R. (1999). Is 'exploratory talk' productive talk? In K. Littleton \& P. Light (Eds.). Learning with Computers: Analysing Productive Talk. London: Routledge.

Mercer, N., \& Littleton, K. (2007). Dialogue and the Development of Children'sThinking: A Sociocultural Approach. London: Routledge.

Mercer, N. (2008) The Seeds of Time: Why classroom dialogue needs a temporal analysis. Journal of the Learning Sciences, 17(1), 33-59. 
Mercer, N.; Warwick, P.; Kershner, R. \& Kleine Staarman, J. (2010). Can the interactive whiteboard help to provide "dialogic space" for children's collaborative activity? Language and Education, 24 (5), 367-384

Minocha, S. \& Thomas, P. (2007). Collaborative learning in a Wiki environment: Experiences from a software engineering course. New Review of Hypermedia and Multimedia, 13 (2), 187-209.

Moskaliuk, J., Kimmerle, J. \& Cress, U. (2009). Wiki-supported learning and knowledge building: effects of incongruity between knowledge and information. Journal of Computer Assisted Learning, 25, 549-561.

Nussbaum, E. M., Winsor, D. L., Aqui, Y. M., \& Poliquin, A. M. (2007). Putting the pieces together: Online argumentation vee diagrams enhance thinking during discussions. International Journal of Computer-Supported Collaborative Learning, 2 (4), 479-500.

Parker, K. R., \& Chao J. T. (2007). Wiki as a teaching tool. Interdisciplinary Journal of Knowledge and Learning Objects, 3, 57-72.

Rogoff, B. (1990). Apprenticeship in Thinking: Cognitive Development in Social Context. Oxford, Oxford University Press.

Rojas-Drummond, S.M. \& Peón, M. (2004). Exploratory talk, argumentation and reasoning in Mexican primary school children. Language and Education, 18(6), 539557.

Rojas-Drummond, S., Littleton, K,. Hernandez, F. \& Zúñiga, M. (2010). Dialogical interactions among peers in collaborative writing contexts. In: K. Littleton \& C. Howe (eds). Educational Dialogues, Understanding and Promoting Productive Interaction. London: Routledge, pp. 128-148.

Rommetveit, R. (1992). Outlines of a dialogically based social-cognitive approach to human cognition and communication. In A. H. Wold (Ed.), The dialogical alternative: Towards a theory of language and mind. Oslo: Scandinavian University Press.

Strijbos, J. W., Kitrschner, P. A., \& Martens, R. L. (2004). What we know about CSCL... and what we do not (but need to) know about CSCL. In Strijbos, Kirschner \& Martens (Eds.), What we know about CSCL: An implementing it in higher education (pp. 245-259). Dordrecht, The Netherlands: Kluwer.

Van der Meijden, H. (2005). Knowledge construction through CSCL: Student elaborations in synchronous, asynchronous and three-dimensional learning environments. Unpublished doctoral thesis, Radboud University, Nijmegen, The Netherlands.

Vygotsky, L. S. (1978). Mind in society: The development of higher psychological processes. Cambridge: Harvard University Press.

Wegerif, R. \& Mercer, N. (1997a). A dialogical framework for researching peer talk. In R. Wegerif and P. Scrimshaw (Eds.). Computers and talk in the primary classroom, (pp. 49-65). Clevedon: Multi-lingual Matters.

Wegerif, R. \& Mercer, N. (2000). Language for thinking. In Cowie, H., Aalsvoort, D. \& Mercer, N. New perspectives in collaborative learning. Oxford: Elsevier.

Wegerif, R. \& Dawes, L. (2004). Thinking and learning with ICT. London and NY: RoutledgeFalmer. 
Wegerif, R.; Perez Linares, J. Rojas-Drummond, S.; Mercer, N.; Velez, M. (2005). Thinking together in the UK and Mexico: transfer o fan educational innovation. Journal of Classroom Interaction, 40 (1), 40-47.

Wegerif, R. (2007). Dialogic Education and Technology. New York: Springer.

Wertsch, J. V. (1991). Voices of the mind: A sociocultural approach to mediated action. London: Harvester Wheatsheaf.

Wheeler, S., Yeomans, P., \& Wheeler, D. (2008). The good, the bad and the wiki: Evaluating student-generated content for collaborative learning. British journal of educational technology, 39 (6), 987-995.

Yukawa, J. (2006). Co-reflection in online learning: Collaborative critical thinking as a narrative. Computer-Supported Collaborative Learning, 1, 203-228. 